\title{
THANKS FOR THE MEMORIES: KEN AT PRINCETON UNIVERSITY (1968-1972) AS SEEN BY LEONARD H. CAVENY
}

\section{KENNETH KUO'S DISSERTATION RESEARCH}

Kenneth K. Kuo and I became colleagues in 1969. He was a first-year PhD student and I was a new staff member in Martin Summerfield's Princeton University laboratory. Ken's manner and industrial experience with Garrett AiResearch Manufacturing Company equipped him with a focus and presence beyond that of several other graduate students. Naturally, Martin Summerfield recognizing Ken's analytical capability steered him toward a purely analytical dissertation rather than research involving an elaborate experimental apparatus. Only a few students were worthy of that concession and distinction by Professor Summerfield. Very simply, Professor Summerfield valued Ken's potential as an analyst and desired that his dissertation research took full benefit.

The early 1970s rapidly evolving availability to "super computers" enabled Ken's considerations of complex combustion processes requiring computationally intensive numerical solutions. More important, the more capable computers allowed Professor Summerfield to demand that Ken include all of the essential physics and minimize assumptions.

To fulfill the Martin Summerfield vision of addressing analytically very complex combustion phenomena, Ken became the analyst in a three-prong team approach. Professor Summerfield's recognition of worthy physical situations was the leadership prong. Implementing the third prong required a national leader in solving complex equations using super computers. In anticipation, Professor Summerfield brought into his inner circle Professor Robert J. Vichnevetsky, Department of Computer Sciences, Rutgers University in New Jersey, nationally known for numerical solutions to coupled sets of partial differential equations with complex boundary conditions. In that era, numerical solutions required a high level of coding efficiency to avoid the budget-busting expenses and limitations of computer availability. Brute-force finite differences and canned subroutines were not options. Dollars per hour for computer time required a campaign to establish a well thought out and efficient solution. Professor Vichnevetsky's experience assured an expertly designed and efficient path to a validatable solution.

The physical process that Professor Summerfield defined and Ken addressed was flame propagation and ultrahigh burning rates during the combustion and pressurization of porous media (granular solid propellant) in a long-closed chamber. Solving the three-vector formulation of partial differential equations proceeded as a simultaneous solution, plus coupled equations for void spaces and surface temperature of the media. The solution involved central differences in space and a generalized implicit difference scheme in time. Two features defining the approach were the use of quasilinearization techniques to deal with the nonlinear terms and the treatment of boundary conditions by a method of characteristics. At the time, this complexity was difficult to grasp much less prepare for and implement as a solution. Professor Vichnevetsky was and remains a taskmaster, insisting that every key step in the solution be understood, validated, and optimized. I observed from the sidelines how Ken was up to the intellectual and persistence challenges Professor Vichnevetsky imposed. Ken's solution (Kuo et al., 1973) correlated 


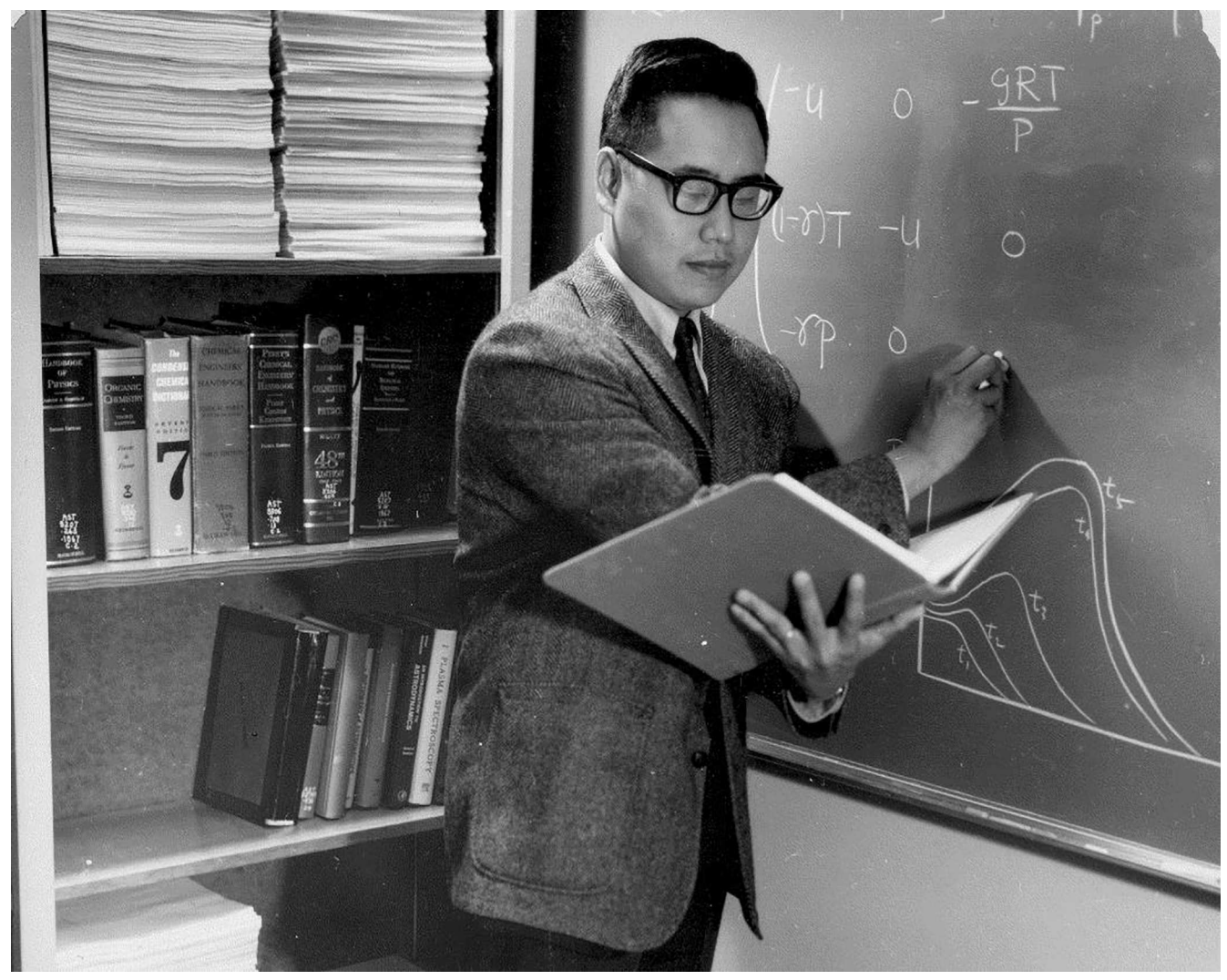

Kenneth Kuo's photograph for Martin Summerfield's laboratory gallery, one of a few where the student is not standing by an apparatus (1971)

and explained the observations and transient measurements being produced by our colleague in a nearby laboratory. Establishing a useful numerical method to handle hyperbolic partial differential equations with extraneous boundary conditions was an important contribution that was extended to other combustion situations by Ken and other graduate students. To this day, I remain impressed by Ken's performance on both the physical and numerical aspects of this important research.

During his postdoctoral year (1973), Ken applied and extended what he learned to help Arie Peretz solve the equally challenging set of partial differential equations with more difficult boundary conditions for the start-up transients of solid-propellant rocket motors (Peretz et al., 1973).

Ken was one of the few Martin Summerfield graduate students who did not do a major experiment. However, starting in the mid-1970s, he established what is now the most formidable and complete high-pressure combustion and solid-propellant propulsion laboratory in an American university, the famous Penn State High Pressure Combustion Laboratory. (Martin Summerfield's fully functioning and staffed laboratory was disbanded by 1980, after Martin left Princeton University in 1978 and I left in 1980.) Fortunately, Ken was able to install several larger items from Martin Summerfield's laboratory, e.g., $10 \mathrm{~cm} \mathrm{ID,} 18 \mathrm{~m}$ long shock tunnel, and a $500 \mathrm{MPa}$ combustor. 


\section{KENNETH K. KUO AS A COLLEAGUE}

Kenneth K. Kuo remains the most sincere, gracious, and conscientious of my colleagues. Those of us who worked projects with Ken soon learned another of his traits-intensity. He had a tendency to hold tenuously his position on technical interpretations. On several occasions, Ken and I fell into contentious and heated arguments on formulations and apparatus. Observers concluded we would never speak again. Not so! Once the reasons for the contention were resolved or bypassed, Ken's ability to return immediately to his naturally gracious and pleasant manner is a trait to aspire to.

A particularly contentious collaboration was our $1975 \$ 10,000$ consulting contract with NASA MSFC to predict the ignition transients of the Space Shuttle solid rocket motor (SRM) booster. This involved extending Arie Peretz's dissertation solution and computer program for analyzing his window motor results. I had extended it to predict high-performance practical motors. Ken's and my collaboration included incorporating extensions for predicting the ignition and flow in the SRM's four circumferential slots between its four segments. After the first series of checkout runs, problems with the effect of slot flow on chamber momentum were apparent. After several days of disagreement, a physically pleasing and correct formulation was achieved. We predicted the SRM, agreed with the duty cycle of Thiokol's head-end igniter, and discovered transient wave forms months before NASA and Thiokol's first SRM test firing (Caveny et al., 1980; Caveny and Kuo, 1976). Martin Summerfield highly praised our contribution to the SRM and used that praise in future commendations.

Ken's and my last collaboration was the two-year process of organizing the Martin Summerfield Centennial Session for the January 2016 AIAA SciTech Conference. We lined up an impressive agenda to be fulfilled by Martin's colleagues and students. Two days before finalizing our place on the program, Ken and I recognized that too many of the prospective participations could no longer commit, mostly because of uncertain health. That was when Ken informed me he was concerned about his own health and participation. With anguish, I withdrew the Centennial Session. Similarly, the presentation (one hour) and aerospace applications paper accepted for the regular Propellants \& Combustion technical session, "Martin Summerfield's Contributions to Jet Propulsion-A Centennial Remembrance" with Ken as lead author, had to be withdrawn. Sadly, within the year, we lost several of Martin Summerfield's former graduate students, including Ken.

With Ken's passing, the United States and our World's combustion and propulsion community lost a driving force and leader who is unlikely to be replaced as propulsion research wanes in the United States. Our worldwide community lost a friend and colleague whose pleasant manner and tenacious drive can never be replaced.

\section{REFERENCES}

Caveny, L.H. and Kuo, K.K., (1976) Ignition Transients of Large Segmented Rocket Boosters, NASA Contractor Report No. CR-150162, NASA-George C. Marshall Space Flight Center.

Caveny, L.H., Kuo, K.K., and Shackelford, B.W., (1980) Thrust and Ignition Transients of the Space Shuttle Solid Rocket Motor, AIAA J. Spacecraft Rockets, 17(6), pp. 489-495.

Kuo, K.K., Vichnevetsky, R.J., and Summerfield, M., (1973), Theory of Flame Front Propagation in Porous Propellant Changes under Confinement, AIAA J., 11(4), pp. 444-451.

Peretz, A., Kuo, K.K., Caveny, L.H., and Summerfield, M., (1973) Starting Transients of Solid Propellant Motors with High Internal Gas Velocities, AIAA J., 11(12), pp. 1719-1727.

Volume 16, Issue 1, 2017 